\title{
INVESTIGATION OF AUTO-IGNITION OF OCTANE-CNG MIXTURE IN HCCI ENGINE
}

\author{
Firmansyah* and A. Rashid. A. Aziz \\ Center for Automotive Research and Electric Mobility, \\ Universiti Teknologi PETRONAS \\ Perak Darul Ridzuan, 31750, Malaysia \\ Email: firmansyah@petronas.com.my \\ Phone: +6053688102
}

\begin{abstract}
Homogeneous Charge Combustion Ignition (HCCI) operating principles have been widely investigated, yet the uncontrollable combustion of HCCI is the major obstacle in its development. The combustion characteristics of single fuels have been widely investigated as the fuel is the most influential factor that determines the HCCI combustion behavior. However, investigations of auto-ignition behavior for multiple fuels have not been carried out. This paper investigates various fuel compositions of Octane and compressed natural gas (CNG), ranging from 10-100\% Octane/CNG. The investigation was done in a constant volume chamber with an $820{ }^{\circ} \mathrm{C}$ cartridge heater. Three lambdas were tested for each fuel mixture, namely $0.8,1$, and 1.2. From the results, it was found that the mixture composition has a major effect on the output of the combustion of dual fuel and a $20 \mathrm{~ms}$ injection gap shows better combustion results due to the higher percentage of Octane in the hotter regions, as well as the more homogeneous mixture created. On the other hand, the lambda is a significant parameter that affects the ignition delay, along with the temperature and droplet size of the mixture,
\end{abstract}

Keywords: Auto-ignition; combustion; dual fuel; iso-Octane; CNG.

\section{INTRODUCTION}

Stringent emissions regulations and significant increases in fuel prices are having a marked effect on the growth rate of automotive technology development with the objective of reducing fuel consumption and improving engine efficiency [1-4] . Controlled auto-ignition based combustion systems such as homogeneous charge compression ignition (HCCI) [5-9], stratified charge combustion ignition (SCCI) [10], premixed charge compression ignition (PCCI) [11] and reactivity charge compression ignition (RCCI) $[12,13]$ are recent engine developments with high efficiency, and low emissions and fuel consumption. These combustion systems are proven to be able to significantly reduce the fuel consumption and exhaust emission, but with drawbacks in performance and operating range.

The fuel type is the most significant parameter in the auto-ignition behavior of a mixture $[14,15]$ in controlled auto-ignition based combustion systems such as HCCI. A significant number of experiments and simulations aimed at improving the understanding of the auto-ignition process have been carried out [16-18]. These earlier experiments were done with either a constant volume chamber, shock tube or rapid 
compression machine (RCM). Furthermore, most of these investigations used a primary reference fuel (PRF) composition that had similar ignition delay properties to those of commercial fuel in order to get a better understanding of the auto-ignition process [19]. The most common PRFs are heptane and iso-Octane [20]. It was found that the low temperature reaction is dominant in heptane, diesel or any other high reactivity fuel auto-ignition process, as shown by the occurrence of cool flame phenomena and the existence of a negative temperature coefficient (NTC) [21]. On the other hand, the high temperature reaction is dominant in the iso-Octane auto-ignition process [22]. Nevertheless, these characterizations have been mainly done on single fuels and are yet to be applied on a multi-fuel system. Earlier research indicates that each fuel has its own properties that can be utilized in the effort to control the auto-ignition process [22]. In order to fully utilize every fuel's characteristics, combinations of fuels are proposed as the solution in controlling the auto-ignition process. The dual fuel option in the CAI combustion system generally focuses on the combination of high reactive fuels such as diesel and heptane with a low reactive fuel such as gasoline [23]. The high reactive fuel acts as the pilot igniter for the low reactive fuel in order to control and start the combustion process. A predictable and short combustion delay is shown by this fuel combination, and increases the controllability of the combustion process. Furthermore, the fuel combination method is also able to increase the combustion output and reduce the exhaust emission [19].

On the basis of controlling the combustion process by fuel combination, this paper attempts to explore the possibilities of a low reactivity fuel combination, namely octane and CNG, where both fuels have high octane numbers, 100 and 120 [24, 25] respectively. Furthermore, the variation of mixture distribution will also be examined by varying the injection gaps between the fuels.

\section{EXPERIMENTAL SETUP}

This study performs an experimental investigation on the auto-ignition behavior of dual fuel (Octane-CNG) in a constant volume combustion chamber shown in Figure 1. A probe heater is used to increase the temperature inside the combustion chamber. The heater temperature is varied from $400{ }^{\circ} \mathrm{C}$ to $800{ }^{\circ} \mathrm{C}$ in order to get an auto-ignition from the mixture. However, a preliminary experiment showed that the heater temperature must be set above $800{ }^{\circ} \mathrm{C}$ in order to get a stable auto-ignition from the mixture at a combustion chamber pressure of 1 bar. Furthermore, oxygen with purity $99.5 \%$ is used to replace air in order to reduce the complexity of the reaction and increase the probability of auto-ignition occurrence. In the experiment, the Octane-CNG fuel mixture was tested and the composition was varied from 10-100\% Octane/CNG. The combustion data for these mixtures were obtained for various lambdas $(0.8,1$, and 1.2) in order to get the effect of the lambda on the combustion of the fuel. The injector used was a Siemens Deka 4 with 3 bars injection pressure and $4.3 \mathrm{~g} / \mathrm{s}$ delivery rate (manufacturer's specification and fueled with gasoline). Due to density variations of the fuels, the calibration process was carried out in the ambient condition for each fuel to measure the actual delivery rate of the injector. It was found that the delivery rate for Octane is $4.6 \mathrm{~g} / \mathrm{s}$. On the other hand, the Orbital CNG injector was used with a low injection pressure, $7.5 \mathrm{bar}$, and $7.2 \mathrm{~g} / \mathrm{s}$ mass flow rate. The injectors were positioned at 
$90^{\circ}$ relative to each other and both directly injected into the combustion chamber (Figure 1). The lambda was generated by calculating the stoichiometric reaction between the fuels and oxygen. From the calculation, the required fuel amount of constant volume was determined and translated to the injector opening by dividing the total fuel required by the injector delivery rate. Two injection gaps were tested, $0 \mathrm{~ms}$ and $20 \mathrm{~ms}$, to vary the mixture distribution inside the combustion chamber, with Octane and CNG injected consecutively. The injection gap between the injectors is controlled by an injector driver that follows the input from the stoichiometric calculations of the fuels. During the experiment, two-stage flushing was applied. The chamber was vacuumed to clear all the leftovers from the previous combustion process, then oxygen was introduced for a period of $15 \mathrm{~s}$ to ensure that there was no air left inside the chamber. The next step was to increase the heater temperature to the set point before the fuel was injected into the chamber. A single trigger point was used to inject the fuel 0.4 $\mathrm{s}$ after the pressure data acquisition started.

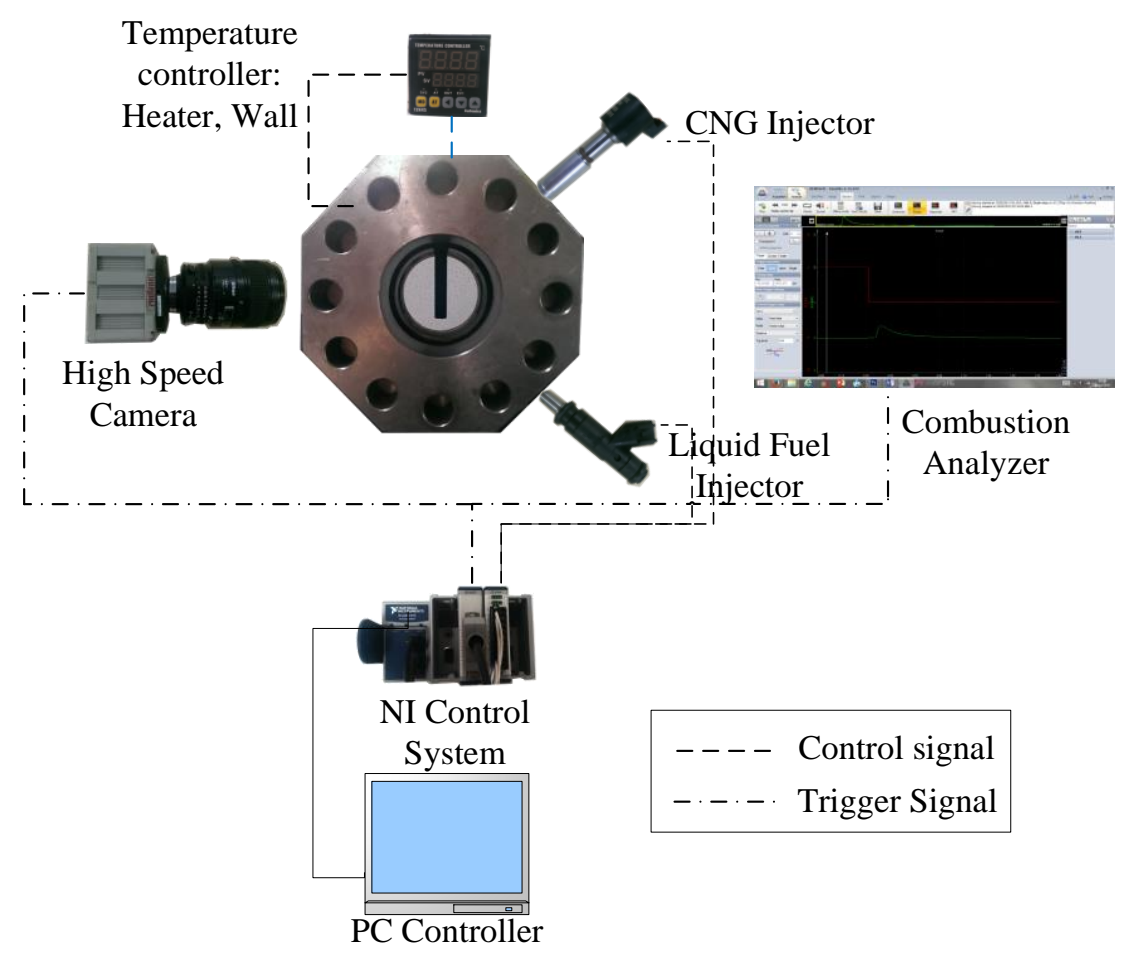

Figure 1. Experimental setup of the constant volume chamber.

\section{RESULTS AND DISCUSSION}

In this dual-fuel configuration, both fuels have high Octane numbers. However, Octane is used as the igniter for CNG due to its auto-ignition temperature and because the Octane number is lower than CNG. For this reason, the Octane is injected before CNG in the 0 and $20 \mathrm{~ms}$ injection gap arrangement. The effect of the injection gap at various fuel compositions at lambda 0.8 is shown in Figure 2(a). The mixture composition causes significant changes in the combustion. Increasing trends on the combustion efficiency, maximum pressure and total heat release can be observed in Figure 2 for all 
the tested lambdas. It is also shown that the lower limit of Octane composition in order to have an auto-ignition is $40 \%$. These trends show that the CNG is suppressing the combustion up to the limit where the Octane-oxygen ratio is too lean, as well as at higher mixture Octane numbers.

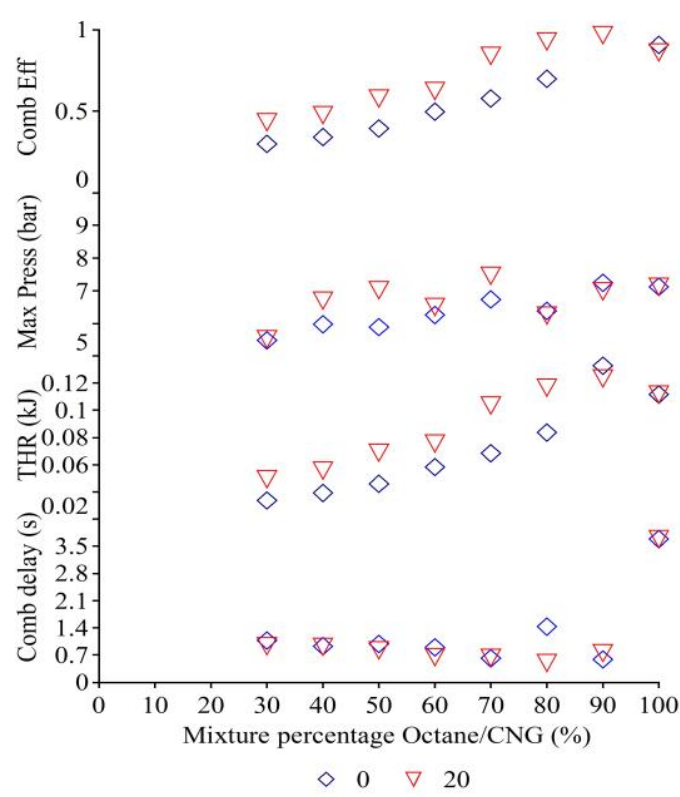

(a)

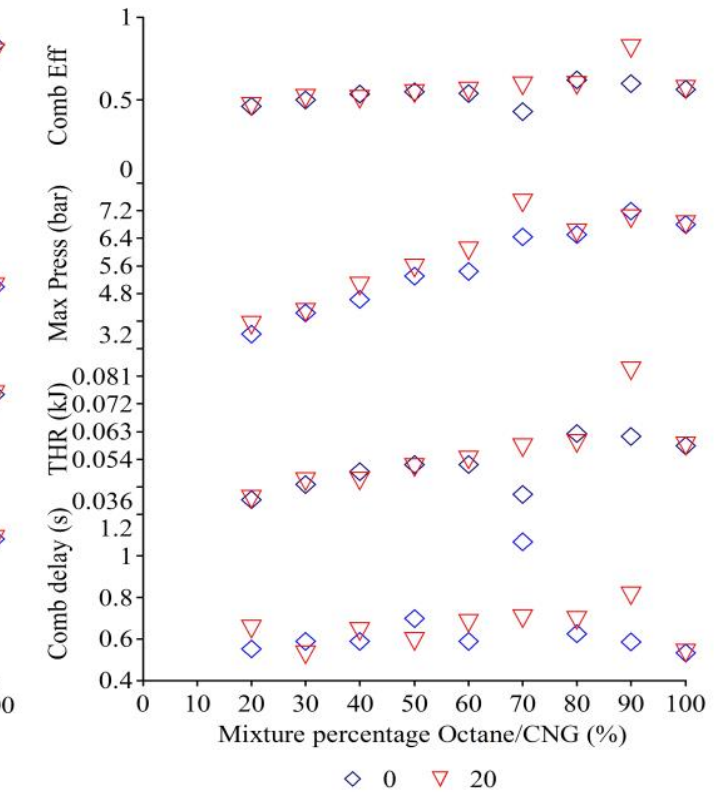

(b)

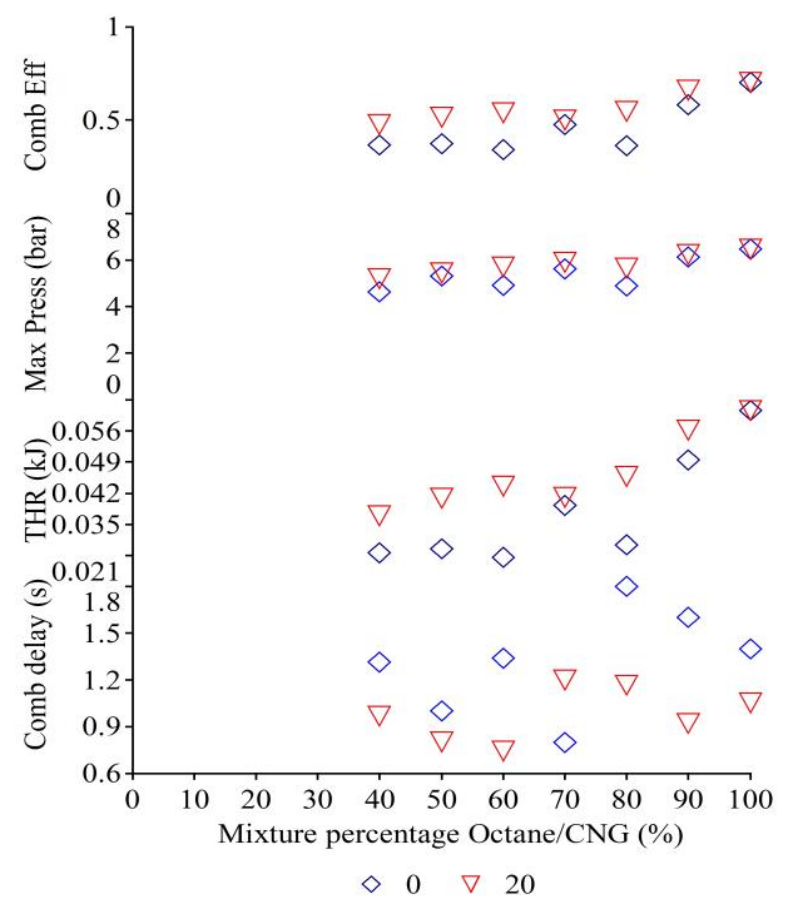

(c)

Figure 2. Effect of injection gap in the combustion of Octane-CNG mixtures at lambda (a) 0.8 , (b) 1 and (c) 1.2 .

Nevertheless, the $20 \mathrm{~ms}$ injection gap results in better combustion performance compared to the $0 \mathrm{~ms}$ injection gap. This behavior is due to the difference in mixture distribution inside the chamber. The injectors were positioned at $90^{\circ}$ from each other (Figure 2). Most of the Octane is at the bottom part of the chamber due to the collision 
between the Octane injection and CNG injection, while on the other hand the higher temperature inside the chamber is located at the top of the chamber (Figure 3). This condition creates highly unfavorable conditions for combustion, with high fuel stratification (fuel with low Octane number) in the low temperature region while the high temperature region is combined with high Octane fuel (CNG). This condition resulted in a lower maximum pressure and total heat release rate (THR), with a longer combustion delay. The $20 \mathrm{~ms}$ injection gap produces a different mixture distribution from that with a $0 \mathrm{~ms}$ injection gap. During the Octane injection process, Octane reaches the upper side of the chamber, closing in to the hot region of the chamber, and then the $\mathrm{CNG}$ is introduced (Figure 3). In this case, some vaporization of Octane occurs before the mixture becomes homogeneous due to the CNG injection. The high stratification of Octane (in the high temperature region) creates a very favorable environment for combustion to occur and the high-speed CNG injection promotes the mixing process and creates a higher homogeneity level. This homogeneous mixture will produce a better combustion output. The combination of stratification in the early stage and homogeneity in the later stage enables the $20 \mathrm{~ms}$ injection gap to produce higher combustion performance [26].

\begin{tabular}{|c|c|c|c|c|}
\hline \multirow{2}{*}{$\begin{array}{l}\text { Injection } \\
\text { gap }\end{array}$} & \multicolumn{4}{|c|}{ Time after injection starts } \\
\hline & $0 \mathrm{~ms}$ & $10 \mathrm{~ms}$ & $25 \mathrm{~ms}$ & $100 \mathrm{~ms}$ \\
\hline $0 \mathrm{~ms}$ & & & & \\
\hline $20 \mathrm{~ms}$ & & & & \\
\hline
\end{tabular}

Figure 3. Fuel distribution for Octane-CNG mixture with $0 \mathrm{~ms}$ and $20 \mathrm{~ms}$ injection gaps.

The mixture Octane numbers resulting from the mixture variation range from 100-120 research Octane numbers (RON). Figure 4 shows the effect of the mixture Octane number on the combustion of the Octane-CNG mixtures. Linearly decreasing trends of maximum pressure, combustion efficiency and THR can be observed in both injection gaps and a significant decrease is observed in the heat release of lambda 0.8 with increase of the mixture Octane number. Due to the low fuel injection pressure used in this experiment (3 bar), which creates a large droplet size [27], the ignition delay and combustion behavior are mainly affected by physical rather than chemical delay, which 
primarily comes from droplet heating and evaporation of the liquid fuel [28]. It is shown in Figure 4 that lambdas 1.2, 0.8 and 1 respectively result in decreasing ignition delay for all Octane numbers and injection gaps. This trend indicates that the lambda is a significant parameter in controlling ignition delay as well as temperature. Voglsam and Winter [29] showed the effect of temperature variation on the ignition delay of Octane in stoichiometric conditions. A logarithmic scale ignition delay was observed in the temperature range from $700-1250 \mathrm{~K}$. The ignition delays for $800{ }^{\circ} \mathrm{C}$ reported by Voglsam and Winter [29] are in the range of 0.5-1 ms, while in this experiment the ignition delay ranges from 100-2000 ms, which is a few hundred times greater. The physical delay from droplet heating and fuel evaporation, along with the CNG addition in the system, are the main reasons for these significant differences.

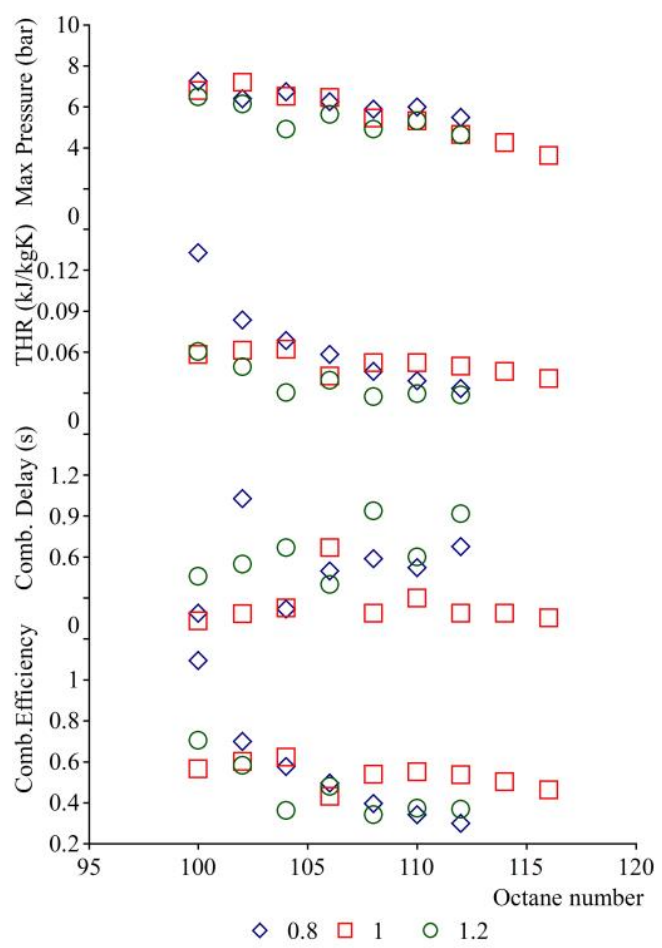

(a)

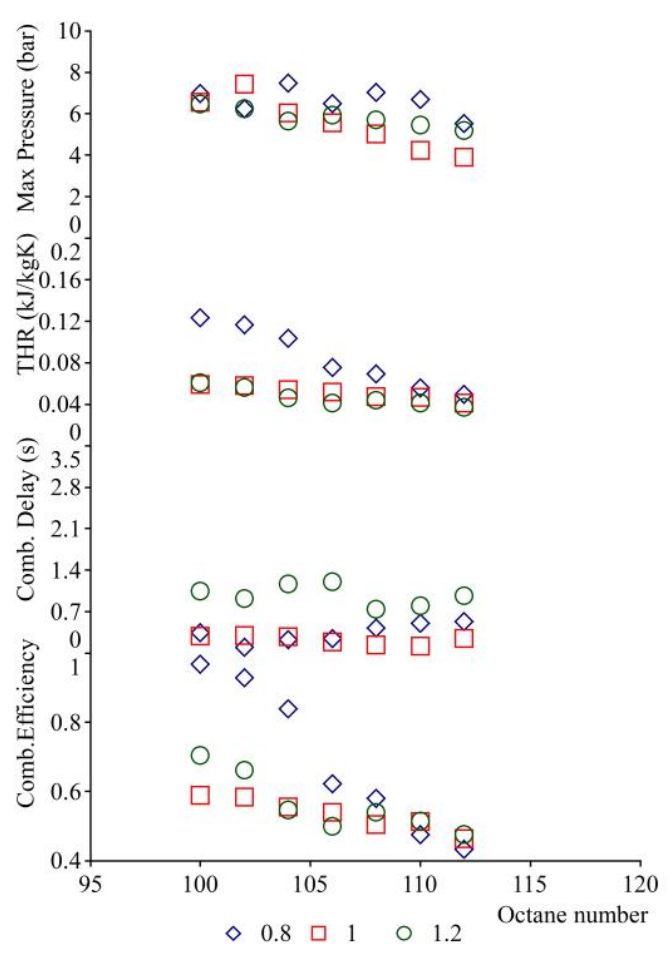

(b)

Figure 4. Effect of Octane number on the combustion of Octane-CNG mixture at various lambdas at (a) $0 \mathrm{~ms}$ injection gap and (b) $20 \mathrm{~ms}$ injection gap.

\section{CONCLUSIONS}

The results show the significance of the mixture composition, lambda and injection gap parameters in dual-fuel combustion of Octane-CNG mixture. The mixture composition is proven to be a very important parameter in the auto-ignition of the fuel mixture. The combustion efficiency, THR and maximum pressure decrease with the increase in CNG percentage in the mixtures. The low reactivity of CNG may be the main reason for this trend. The homogeneity level of the mixture affects the combustion, such that the combustion produces higher pressure with a high homogeneity level in the chamber, while the stratified mixture produces less pressure. In the case of low injection pressure, 
the combustion delay is mainly controlled by the physical delay due to vaporization and the droplet heating process, which could increase the combustion delay a few hundred times over the delay caused by the chemical reaction. Furthermore, the ignition delay is mostly affected by the lambda value of the mixture rather than the fuel composition and total octane number of the mixture.

\section{ACKNOWLEDGEMENTS}

The authors would like to be obliged to Universiti Teknologi PETRONAS and Center for Automotive Research and Electric Mobility for providing laboratory facilities and financial assistance under project no. STIRF 12/09.10.

\section{REFERENCES}

[1] Iqbal Sherazi H, Li Y. Homogeneous Charge Compression Ignition engine: A technical review. 17th International Conference on Automation and Computing 2011. p. 315-20.

[2] Kamil M, Rahman MM, Bakar RA. Performance evaluation of external mixture formation strategy in hydrogen fueled engine. Journal of Mechanical Engineering and Sciences. 2011;1:87-98.

[3] Kamil M, Rahman MM, Bakar RA. Integrated simulation model for composition and properties of gases in hydrogen fueled engine. International Journal of Automotive and Mechanical Engineering. 2013;8:1242-155.

[4] Kamil M, Rahman MM, Bakar RA. An integrated model for predicting engine friction losses in internal combustion engines. International Journal of Automotive and Mechanical Engineering. 2014;9:1695-708.

[5] Noguchi M, Tanaka Y, Tanaka T, Takeuchi Y. A Study on Gasoline Engine Combustion by Observation of Intermediate Reactive Products during Combustion. SAE Technical Paper No 790840. 1979.

[6] Onishi S, Jo S, Shoda K, Jo P, Kato S. Active Thermo-atmosphere Combustion (ATAC) - A New Combustion Process for Internal Combustion Engines. SAE Technical Paper 790501. 1979.

[7] Mohanamurugan S, Sendilvelan S. Emission and combustion characteristics of different fuel In A HCCI engine. International Journal of Automotive and Mechanical Engineering. 2011;3:279-92.

[8] Aziz Hairuddin A, Wandel AP, Yusaf T. Effect of different heat transfer models on a diesel homogeneous charge compression ignition engine. International Journal of Automotive and Mechanical Engineering. 2013;8:1292-304.

[9] Hairuddin AA, Wandel AP, Yusaf T. An Introduction to a Homogeneous Charge Compression Ignition Engine. Journal of Mechanical Engineering and Sciences. 2014;7:1042-52.

[10] Chen Z, Yao MF, Zheng ZQ, Zhang B, Xing Y. Optimal strategy for HCCI combustion of dual-fuel. Ranshao Kexue $\mathrm{Yu}$ Jishu/Journal of Combustion Science and Technology. 2006;12:142-6.

[11] Kocher LE, Hall CM, Stricker K, Fain D, Alstine D, Shaver GM. Robust oxygen fraction estimation for conventional and premixed charge compression ignition engines with variable valve actuation. Control Engineering Practice. 2014;29:187-200. 
[12] Firmansyah AR, Aziz A. The Combustion Behavior Analysis of Dual Fuel HCCI using the Shell Model. Journal of Applied Sciences. 2011;11:1559-65.

[13] Firmansyah, Aziz ARA, Heikal MR. Double stage wiebe: An approach to single zone modeling of dual fuel HCCI combustion. Asian Journal of Scientific Research. 2013;6:388-94.

[14] Berntsson AW, Denbratt I. HCCI combustion using charge stratification for combustion control. SAE Technical Papers. 2007;2007:776-90.

[15] Krasselt J, Foster D, Ghandhi J, Herold R, Reuss D, Najt P. Investigations into the Effects of Thermal and Compositional Stratification on HCCI Combustion Part I : Metal Engine Results. SAE Int J Engines. 2009;2:1034-53.

[16] Minetti R, Carlier M, Ribaucour M, Therssen E, Sochet LR. A rapid compression machine investigation of oxidation and auto-ignition of n-Heptane: Measurements and modeling. Combustion and Flame. 1995;102:298-309.

[17] Risberg P, Kalghatgi G, Ångstrom H-E, Wåhlin F. Auto-ignition quality of Diesel-like fuels in HCCI engines. SAE International. 2005.

[18] Lu X, Hou Y, Zu L, Huang Z, Lü X. Experimental study on the auto-ignition and combustion characteristics in the homogeneous charge compression ignition (HCCI) combustion operation with ethanol/n-heptane blend fuels by port injection. Fuel. 2006;85:2622-31.

[19] Saxena S, Bedoya ID. Fundamental phenomena affecting low temperature combustion and HCCI engines, high load limits and strategies for extending these limits. Progress in Energy and Combustion Science. 2013;39:457-88.

[20] Zheng J, Yang W, Miller DL, Cernansky NP. Prediction of Pre-ignition Reactivity and Ignition Delay for HCCI Using a Reduced Chemical Kinetic Model. Society of Automotive Engineers. 2001:1-8.

[21] Fu X, Aggarwal SK. Two-stage ignition and NTC phenomenon in diesel engines. Fuel. 2015;144:188-96.

[22] Yang Y, Dec JE, Dronniou N, Sjöberg M. Tailoring HCCI heat-release rates with partial fuel stratification: Comparison of two-stage and single-stage-ignition fuels. Proceedings of the Combustion Institute. 2011;33:3047-55.

[23] Yang B, Yao M, Cheng WK, Li Y, Zheng Z, Li S. Experimental and numerical study on different dual-fuel combustion modes fuelled with gasoline and diesel. Applied Energy. 2014;113:722-33.

[24] Bradley D, Head RA. Engine autoignition: The relationship between octane numbers and autoignition delay times. Combustion and Flame. 2006;147:171-84.

[25] Hairuddin AA, Yusaf T, Wandel AP. A review of hydrogen and natural gas addition in diesel HCCI engines. Renewable and Sustainable Energy Reviews. 2014;32:739-61.

[26] Ito S, Ikeda H, Jung DW, Iida N. Potential of Stratification Charge for Reducing Pressure-Rise Rate in HCCI Engines Based on Multi-Zone Modeling and Experiments by using RCM. SAE Technical Paper. 2013.

[27] Nuyttens D, Baetens K, Schampheleire M, Sonck B. Effect of nozzle type, size and pressure on spray droplet characteristics. Biosystems Engineering. 2007;97:333-45.

[28] Sazhina EM, Sazhin SS, Heikal MR, Babushok VI, Johns RJR. A Detailed Modelling of the Spray Ignition Process in Diesel Engines. 2000. p. 317-44.

[29] Voglsam S, Winter F. A global combustion model for simulation of n-heptane and iso-octane self ignition. Chemical Engineering Journal. 2012;203:357-69. 